\title{
Interconnected reproductive and vegetative remains of Populus (Salicaceae) from the middle Eocene Green River Formation, northeastern Utah
}

William D. Tidwell

Steven R. Manchester

David L. Dilcher

Follow this and additional works at: https://scholarsarchive.byu.edu/facpub

Part of the Geology Commons

\section{Original Publication Citation}

Interconnected reproductive and vegetative remains of Populus (Salicaceae) from the middle Eocene Green River Formation, northeastern Utah. Steven R. Manchester, David L. Dilcher, and William D. Tidwell American Journal of Botany (January 1986), 73(1):156-16

\section{BYU ScholarsArchive Citation}

Tidwell, William D.; Manchester, Steven R.; and Dilcher, David L., "Interconnected reproductive and vegetative remains of Populus (Salicaceae) from the middle Eocene Green River Formation, northeastern Utah" (1986). Faculty Publications. 1450.

https://scholarsarchive.byu.edu/facpub/1450

This Peer-Reviewed Article is brought to you for free and open access by BYU ScholarsArchive. It has been accepted for inclusion in Faculty Publications by an authorized administrator of BYU ScholarsArchive. For more information, please contact ellen_amatangelo@byu.edu. 


\title{
INTERCONNECTED REPRODUCTIVE AND VEGETATIVE REMAINS OF POPULUS (SALICACEAE) FROM THE MIDDLE EOCENE GREEN RIVER FORMATION, NORTHEASTERN UTAH ${ }^{1}$
}

\author{
Steven R. Manchester, David L. Dilcher, \\ AND William D. TiDWELL ${ }^{2}$
}

\begin{abstract}
Departments of Geology and Biology, Indiana University, Bloomington, Indiana 47405
\end{abstract}
${ }^{2}$ Department of Botany and Range Science, Brigham Young University, Provo, Utah 84602

\section{A B S T R A C T}

\begin{abstract}
A new specimen from the Middle Eocene Evacuation Creek Member of the Green River Formation in northeastern Utah shows a twig with several leaves of Populus wilmattae Cockrell and a fruiting raceme attached. This specimen establishes for the first time the type of fruits borne by $P$. wilmattae and provides additional characters with which to assess its taxonomic and evolutionary status. An associated seed shows attached placental hairs like those of extant species of Populus. The Green River fossil differs from extant Populus species in having basically palmate leaf venation and in bearing its fruiting axis on a young twig. In other aspects, the fossil species is remarkably similar to the extant species Populus mexicana.
\end{abstract}

FossiLs SHOwING actual attachment between leaves, stems, and reproductive organs are exceedingly rare but are the only source of unequivocal proof for "whole plant" reconstructions of fossil species. In this paper we describe a specimen of Populus showing leaves and fruits attached to the same twig preserved in shale from the Middle Eocene Green River Formation of northeastern Utah. Populus is widespread today in temperate Northern Hemisphere floras with 35 species distributed among six sections. The fossil record of Populus extends back to the early Tertiary and is known mainly from isolated leaves (LaMotte, 1952) and fruits (Kirchheimer, 1957).

The earliest probable Populus occurrence known is that of leaves from the late Paleocene Bear Den Member of the Golden Valley Formation, North Dakota (Hickey, 1977, pl. 22, fig. 2, 5; Wing, 1981, p. 267). During the Eocene, leaves with the architecture of Populus were wide-ranging in North America, with occurrences in the Pacific Northwest, the Rocky Mountain, and the Mississippi Embayment regions (Eckenwalder, 1980; Wing, 1981). Populus leaves were first identified in the Green

\footnotetext{
${ }^{1}$ Received for publication 4 June 1985 ; revision completed 21 August 1985 .

This research was supported in part by NSF grants BSR 84-07841 to SRM and DEB 79-10720 to DLD. We thank the collectors, Ed and Ava Cole and Monty Knutson of Wall, South Dakota, for providing the specimen upon which this study is based. We thank Peter Crane and James Eckenwalder for helpful comments on the manuscript.
}

River Formation by Cockrell (1925) and have since been observed at most plant localities of the formation in Utah, Colorado, and Wyoming (MacGinitie, 1969; Grande, 1980). In his monographic treatment of the Green River flora, MacGinitie (1969) recognized two species of poplar coexisting at each locality: $P$. wilmattae Cockrell, with broadly ovate leaves and "two well marked opposite pairs [of secondaries] in the lower third of the leaf"; and $P$. cinnamomoides (Lesquereux) MacGinitie, characterized by slender leaves with a single prominent pair of basal secondaries. Eckenwalder $(1977,1980)$ called attention to heteromorphism in foliage of extant Populus and suggested that the two species recognized by MacGinitie were actually the juvenile ( $P$. cinnamomoides) and mature ( $P$. wilmattae) forms of a single species, and that the two morphotypes be united under the older name, $P$. cinnamomoides. Our own study supports, but does not conclusively confirm, Eckenwalder's hypothesis. For the purposes of convenience in discussion, we maintain the names $P$. cinnamomoides and $P$. wilmattae as morpho-species for leaves of the narrow and broad architecture, respectively.

An exceptional specimen recently recovered from the Middle Eocene Evacuation Creek Member of the Green River Formation in northwestern Utah provides important new information on the Green River poplar. The specimen (Fig. 1) is preserved on a slab of shale and consists of a twig with leaves of $P$. wil- 
mattae and an attached fruiting raceme bearing several valvate capsules. The same slab of shale also shows a dispersed Populus seed and unattached leaves of both $P$. wilmattae and $P$. cinnamomoides. The specimen is important because it demonstrates the degree of foliar heteromorphism present on a single shoot and because it establishes the fruit type borne by this early Tertiary poplar.

MATERIALS AND METHODS-The specimen described here was collected approximately five miles south of Bonanza, UT (I.U. Geol. loc. 15751). The geology and paleontology of this region is reviewed in the context of the entire Green River Formation by MacGinitie (1969) and Grande (1980). The shale was degaged under a dissecting microscope to expose the full length of the axis and to verify connections between the shoot and the fruiting axis and attachments of leaves. The specimen is housed in the paleobotanical collection of Brigham Young University (BYU 3003).

DESCRIPTION-The twig is $3-4 \mathrm{~mm}$ in diameter and measures $6.5 \mathrm{~cm}$ from the apex to where it is broken at the edge of the slab. The lower $5.5 \mathrm{~cm}$ of the twig, although without leaves or branches, bears spirally-arranged circular scars $2 \mathrm{~mm}$ in diameter, protruding 1$1.5 \mathrm{~mm}$, and about $5 \mathrm{~mm}$ apart. Leaves are attached only along the upper $1 \mathrm{~cm}$ and are separated by short (1-2 mm) internodes. Seven leaves are connected to the axis and a few others might be obscured within the sediment. The lowest, and thus earliest, leaves of the spiral are smaller and narrower than the upper leaves. However, the venation of all the leaves is similar.

The petioles are long, 20 to $65(-75$, est.) $\mathrm{mm}, 1-2 \mathrm{~mm}$ wide along most of their length, broadened to $2-3 \mathrm{~mm}$ at the base. As preserved in the shale, the petiole frequently appears disrupted or constricted at its union with the lamina, suggesting that it was originally flattened perpendicular to the plane of the leaf blade and twisted upon compression in sediment. The laminae range from 35 to $100 \mathrm{~mm}$ in length and from 23 to $75 \mathrm{~mm}$ in width. They are ovate to deltoid with a length-to-width ratio of 1.3 (early leaves) to 2.2. The base is obtuse, straightsided, and symmetrical, while the apex is acuminate (early leaf) to long-attenuate. The margin is crenate except along the basal flanks of the blade. Teeth are regularly spaced, even along the apical tip of the leaf, about 4 to $5 \mathrm{~mm}$ apart, and relatively small and rounded. Each tooth has a gland on its upper flank bordering the sinus that is vascularized by a single tertiary vein. The midvein is slightly irregular in course and medium in thickness, tapering conspicuously toward the apex. A pair of intramarginal veins diverge from the midrib at the base of the lamina and proceed just inside the leaf margin to the first teeth. Two prominent pairs of secondaries (or weak lateral primaries) usually arise in the lower $1 / 6$ to $1 / 3$ of the lamina. The lowermost pair arises decurrently from the base of the midvein and then arches smoothly, joining with the superadjacent secondary inside the margin and forming one or two rows of marginal loops. The second pair of secondaries is approximately the same thickness as the first and can be resolved as distinct vascular strands from the base of the lamina but the veins do not actually diverge from the midvein until well above the divergence of the lower pair of secondaries. This pair is also decurrent along the midvein but maintains a lower angle with a more apically oriented course, giving off one or more prominent abmedial branches to the margin and forming larger marginal loops than those of the lower pair of secondaries. The middle one-third of the midvein is without conspicuous secondary veins, although 1 to 3 pairs of intersecondary veins, which extend $1 / 3$ to $1 / 2$ of the distance to the margin, are present. The upper one-third of the midvein gives off 4 to 6 pairs of thin secondaries which arise at lower angles than those below. Those within the accuminate tip form obtuse angles with the midvein. The tertiaries are percurrent, opposite, occasionally alternate, and generally oriented perpendicular to the secondaries. Quaternary veins form a reticulum oriented roughly parallel to the tertiaries. Features of higher order venation are not clearly preserved in the attached leaves. However, certain isolated specimens of the species, such as one figured by MacGinitie (1969, pl. 7, fig. 6), are very well preserved, indicating that the areoles are bounded by veins of fifth order and are 0.5 to $1.0 \mathrm{~mm}$ in size with freely ending veinlets.

The fruiting axis is a raceme arising from the side of the shoot above the lowest leaf but below the highest leaf. It is $40 \mathrm{~mm}$ long, 0.7 $\mathrm{mm}$ diameter, and bears eight helically arranged pedicellate fruits, each arising from a swollen area on the axis. The former attachment of additional fruits is indicated by the presence of 7 additional swollen areas on the axis. Pedicels are $4 \mathrm{~mm}$ (basal fruits) to $3 \mathrm{~mm}$ (apical fruits) and broaden distally, terminating in a conspicuous floral disk scar $(1.5 \mathrm{~mm}$ diam, $0.25 \mathrm{~mm}$ thick) at the base of each fruit. Fruits are capsules with three longitudinal grooves (suggestive of three valves) extending from base to apex. Capsules are ovate-elliptic, 3 to 4.5 

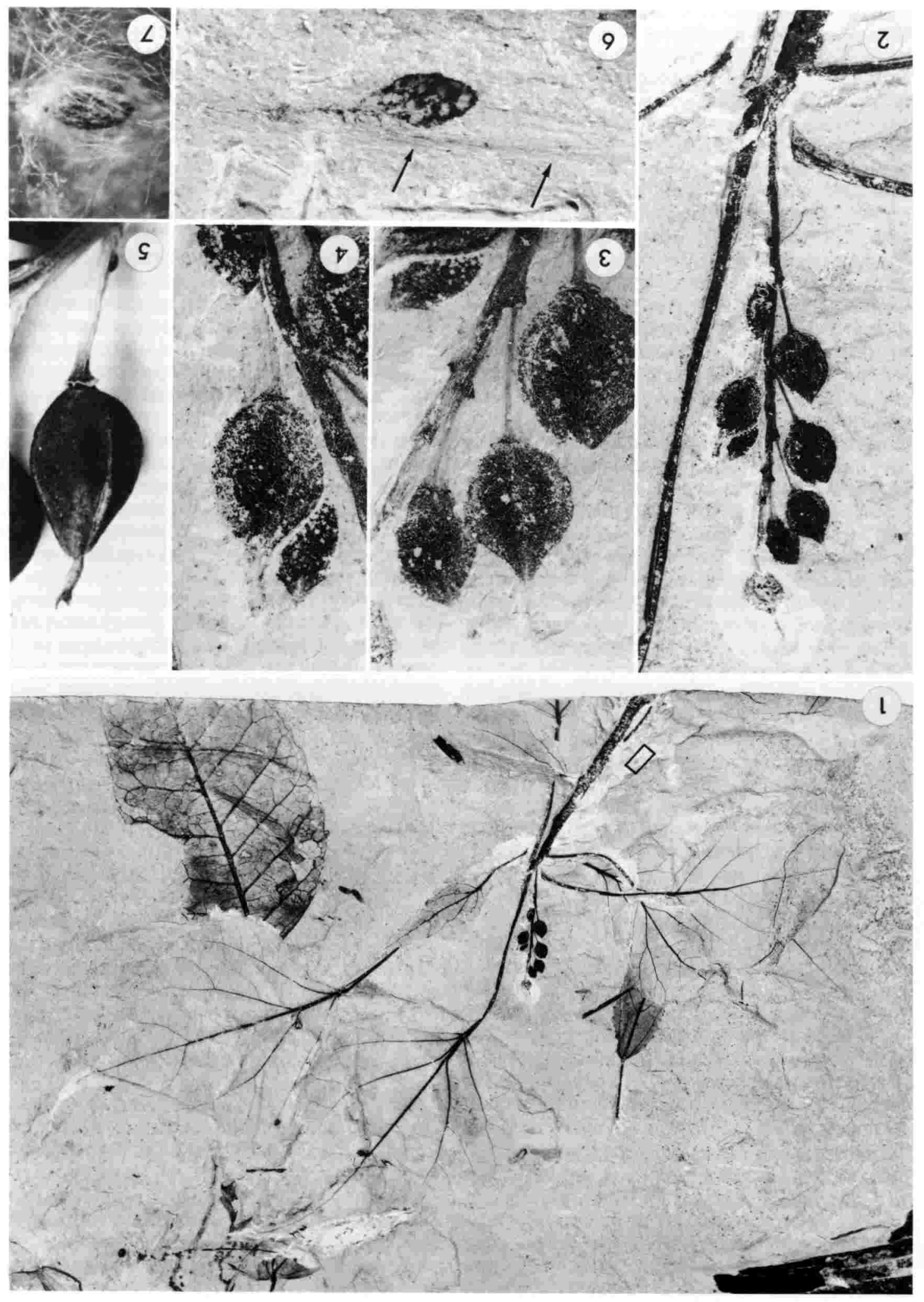
$\mathrm{mm}$ wide and 5 to $7 \mathrm{~mm}$ long, rounded basally, and tapered apically with a persistent style 1$2 \mathrm{~mm}$ long and $0.25 \mathrm{~mm}$ wide; stigmas are not preserved.

Seeds are not preserved within the capsules. A single well-preserved, dispersed seed on the same slab is elliptical, $1.55 \mathrm{~mm}$ long, $0.8 \mathrm{~mm}$ wide, and is attached to a tuft of hairs that probably represent the plumose placenta as in modern Populus.

Discussion - The occurrence of deltoid leaves with salicoid glandular teeth (Hickey and Wolfe, 1975) and long petioles, together with racemose infructescences bearing valvate capsules with distinct floral disks, confirms the identification of this species with Populus. The apparent flattening of the petiole perpendicular to the lamina suggests that these leaves were subject to "quaking," as in many modern Populus species. The associated seed (fig, 6) has an attached hairy placenta and is certainly salicaceous and characteristic of Populus. Whether or not the seed represents the same species as the fruiting twig, its presence suggests that adaptation for wind dispersal of seeds occurred early in the evolution of Salicaceae.

Extant species of Populus are divided into six sections according to Eckenwalder (1977): Turanga, Abaso, Leucoides, Populus (aspens, white poplars), Tacamahaca (balsam poplars), and Aigeros (cottonwoods and black poplars). Characters important in distinguishing the sections include morphology and persistence of the floral disk, presence or absence of marked foliar heteroblasty, overall leaf shape, distribution and shape of foliar teeth, number of carpels, and flattened vs. round petiole crosssection-as well as some features which are not known for our fossil, such as length of anthers, nature of winter buds, and number of ovules per placenta.

We concur with previous authors (MacGinitie, 1969; Eckenwalder, 1977, 1980) that $P$. wilmattae is most similar to $P$. mexicana, the single living species of section Abaso. The leaves of these two species share several features that do not occur in other modern Pop- ulus species, such as percurrent tertiary venation and the continuation of teeth along the flanks of the apical tip of the leaf. The morphological uniformity of the different leaves attached to the fossil twig suggests that foliar heteromorphism along the branch (seasonal heterophylly), a characteristic of some extant sections of Populus, was minimal, as in P. mexicana. Three isolated, narrow leaves of the $P$. cinnamomoides type occur on the same specimen and might represent conspecific foliage of younger trees growing in the same vicinity. If $P$. wilmattae and $P$. cinnamomoides are correctly interpreted as a single species, then marked maturational heteroblasty is another feature of the Green River poplar in common with $P$. mexicana. The new information from reproductive material also supports affinity with section Abaso. The scar subtending each capsule indicates that the floral disks were caducous, as in $P$. mexicana, rather than persistent as in most other sections. However, the capsules of $P$. wilmattae appear to be tri-valvate in contrast to those of $P$. mexicana which are predominantly bi-valvate. The tri-valvate condition of the fossil is common in other extant sections of Populus and might be a primitive character.

We conclude that $P$. wilmattae is an extinct species most closely allied to extant $P$. mexicana. By modifying the modern sectional diagnosis to include tri-valvate capsules, the Green River poplar could be placed in the extant section Abaso. It differs, however, from all living Populus species in two respects. First, the Eocene leaves show a definite tendency toward palmate venation with the lowermost pairs of secondary veins more prominent than those above and visible as separate strands from the midrib that arise independently from the top of the petiole. All of the living species have strictly pinnate venation. Second, the fruiting raceme of the fossil arises from the same young shoot as the leaves, while in modern species the fruiting axes occur on old twigs subtended by leaf scars of a previous season.

Wing (1981) noted that the tendency for palmate venation is typical of Eocene Populus

Fig. 1-7. Eocene and modern Populus. 1. Twig with leaves of $P$. wilmattae Cockerell and attached fruiting raceme. Rectangle indicates position of dispersed seed shown in Fig. 6, BYU 3003, ×0.5. 2. Same specimen, showing attachment of fruiting axis and petioles to twig. Raceme bears at least eight capsules, $\times 1.5$. 3. Detail of raceme, showing attachment of pedicels to raceme and floral disk scars subtending unopened valvate capsules, $\times 5.4$. Another capsule on same axis, showing floral disk scar and style, $\times 5$. 5. P. mexicana ssp. dimorpha (T.S. Brandeg.) Eckenw., from Guasave, Sinaloa, MEX, valvate capsule with floral disk scar and style for comparison with Fig. 5, UC651720 = HS. Gentry 5950 , $\times 5$. 6. Detail of dispersed seed shown in Fig. 1, showing attached placental hairs (arrows), $\times 10$. 7. P. mexicana ssp. dimorpha from El Fuerte, Sinaloa, MEX, seed with attached placental hairs, MO2703736= M. Medina C. $2162, \times 10$. 
leaves from various localities in North America and suggested that it may reflect a "palmate dilleniid ancestry" of the Salicaceae. Architecturally, the leaves of $P$. wilmattae fall between those of extant Populus with true pinnate venation and those of the extant palmate dilleniid genus Idesia (Hickey and Wolfe, 1975) which has true palmate venation.

With only one specimen it is difficult to say whether the position of the fruiting axis shown in Fig. 1 was typical for the species. The raceme appears to have arisen from an axillary bud within the young leafy shoot whereas in extant species the inflorescences develop from buds on old growth of the preceeding season. The fossil species apparently flowered and fruited while the shoot had expanded leaves. In extant Populus species, flowering occurs on old wood prior to the flush of spring leaves, permitting pollination to take place while the branches are relatively free of leaves. Thus the fossil might not have been as well adapted for wind pollination as the extant species.

The Salicaceae appears to have been essentially modern in most fruit and foliage characters by the Middle Eocene. In addition to Populus, the Green River Formation produces abundant foliage of Salix (Brown, 1934; MacGinitie, 1969). A particularly important specimen figured by Brown (1929, as Carpolithus serratifolius) shows two elongate, slender leaves attached to a twig with a terminal fruiting raceme. Re-examination of the specimen shows that the fruits are valvate capsules and indicates that it is attributable to modern Salix. The presence of both extant genera of the Sal- icaceae in the Eocene contrasts with the abundance of extinct genera known in many other angiosperm families at that time.

\section{LITERATURE CITED}

Brown, R. W. 1929. Additions to the flora of the Green River Formation. U.S. Geol. Surv. Prof. Pap. 154 J: 279-299.

- 1934. The recognizable species of the Green River flora. U.S. Geol. Surv. Prof. Pap. 185 C: 45-77.

CoCkerell, T. D. A. 1925. Plant and insect fossils from the Green River Eocene of Colorado. U.S. Nat. Mus. Proc. 66: 1-12.

ECKENWALDER, J. E. 1977. North American cottonwoods (Populus, Salicaceae) of sections Abaso and Aigeros. J. Arnold Arbor. 58: 193-208.

- 1980. Foliar heteromorphism in Populus (Salicaceae), a source of confusion in the taxonomy of Tertiary leaf remains. Syst. Bot. 5: 366-383.

Grande, L. 1980. Paleontology of the Green River Formation, with a review of the fish fauna. Geol. Surv. Wyoming Bull. 63.

HiCKEY, L. J. 1977. Stratigraphy and paleobotany of the Golden Valley Formation (early Tertiary) of western North Dakota. Geol. Soc. Amer. Memoir 150.

$\longrightarrow$, AND J. A. WolfE. 1975. The bases of angiosperm phylogeny: vegetative morphology. Ann. Missouri Bot. Gard. 62: 538-589.

KIRCHHEIMER, F. 1957. Die Laubgewächse der Braunkohlenzeit. Veb Wilhelm Knapp Verlag, Halle (Saale).

LAMotte, R. S. 1952. Catalogue of the Cenozoic plants of North America through 1950. Geol. Soc. Amer. Memoir 51.

MacGinitie, H. D. 1969. The Eocene Green River flora of northwestern Colorado and northeastern Utah. Univ. Calif. Pub. Geol. Sci. 83: 1-140.

WING, S. L. 1981. A study of paleoecology and paleobotany in the Willwood Formation (early Eocene), Wyoming. PhD dissertation, Yale Univ., New Haven. 